\title{
Research on real-driving emissions of heavy tractor under different loads
}

\author{
Yantao Dou*, Yong Li, and Jian Ling \\ CATARC Automotive Test Center (Tianjin) Co., Ltd., China
}

\begin{abstract}
Keywords: real-driving emission, multiple loads, heavy-duty diesel vehicles.

Abstract. The actual road diesel emissions of heavy-duty vehicle is very high, which has been a concern around the world. In 2018, Chinese government promulgated the "China VI" regulations containing real-driving emission test requirements and limits, requiring vehicle manufacturers to effectively control vehicle emissions to meet the requirements of China VI. This article takes a heavy-duty tractor equipped with a "China VI" engine as the research object, and performs actual road emission tests after loading $10 \%, 25 \%, 50 \%, 75 \%$, and $100 \%$ respectively. The results show that NOx emissions are higher at low loads and PN emissions are higher at high loads, and $\mathrm{CO}$ emissions are not sensitive to load changes.
\end{abstract}

\section{Introduction}

On July 3, 2018, the State Council issued the "Three-year Action Plan to Win the Blue Sky Defense War", calling for the fight against pollution of diesel trucks, formulating action plans for the fight against pollution of diesel trucks, and coordinating the management of fuel, roads, and vehicles to ensure that diesel vehicle pollution is reduced. It shows that government departments attach great importance to the actual emissions of diesel vehicles. China VI regulations changed the requirements for real-driving emission boundaries in National $\mathrm{V}$ regulations. The main differences between the actual emission boundary of National VI and the actual emission boundary of National V are shown in the following table. The Phase 6 PEMS test load range is extended to $10 \%-100 \%$. The expansion of the test load range will have a significant impact on the real- emissions . At present, the OEMs lack corresponding development experience in this regard. This article tests the real-driving emissions of the PEMS cycle of a heavy-duty tractor in a country six platform under different loads. In this paper, the actual road emissions of the PEMS cycle of a heavy-duty tractor on a country six platform under different loads were tested accordingly.

Table 1. Comparison of PEMS requirements in different emission stages.

\begin{tabular}{lcc}
\hline Item & China V & China VI b \\
\hline Temperature range & $2 \sim 38^{\circ} \mathrm{C}$ & $-7 \sim 38^{\circ} \mathrm{C}$
\end{tabular}

\footnotetext{
* Corresponding author: douyantao@catarc.ac.cn
} 


\begin{tabular}{lcc} 
Altitude range & $<1000 \mathrm{~m}$ & $<2400 \mathrm{~m}$ \\
Load range & $50 \% \sim 100 \%$ & $10 \% \sim 100 \%$ \\
\hline
\end{tabular}

According to relevant tests, it is found that the distribution of the PEMS cycle operating point of the actual road required by the national six regulations and the engine's WHTC cycle operating point have a large difference. As shown in the following figure, the development of the engine bench calibration During the process, the emissions and fuel consumption of WHTC were balanced and optimized, but under the actual road PEMS cycle conditions, there are still many high-risk conditions at the point of discharge. This also requires us to pay attention to the rectification during the development of the National Sixth Project. Relevant work on the development and calibration of actual road emissions of vehicles, otherwise there will be a large risk of non-compliance in actual road emissions of vehicles in use. Actual road emissions calibration development will have a profound impact on the sustainable development of the company's products and brand power.

aracteristics of oil refining process in China, FCC gasoline occupies the leading position, accounting for about $70 \% \sim 85 \%{ }^{[1-2]}$.

\section{Test device and method}

\subsection{Test equipment}

The test vehicle was a heavy tractor of the N3 category, with a maximum total mass of 42,000 $\mathrm{kg}$. The vehicle is equipped with a high-pressure common rail diesel engine with a displacement of 7.7L and adopts an SCR + DOC + DPF aftertreatment device. The test emission test equipment used OBS-ONE-G12 vehicle emission analysis system produced by HORIBA. Test environment average temperature $11{ }^{\circ} \mathrm{C}$, average atmospheric pressure $102.2 \mathrm{kPa}$, average environmental humidity $66.3 \%$.

The test was performed in accordance with the requirements of Appendix $\mathrm{K}$ of the GB17691-2018 regulation. The vehicles were loaded with 10\%, 25\%, 50\%, 75\%, and 100\% loads, respectively, and then the PEMS test cycle was collected and relevant data was collected to complete the actual roads with different loading Emission test, analysis and discussion of test data.

Table 1. Test road ratio.

\begin{tabular}{cccccc}
\hline Item & Load 10\% & $\begin{array}{c}\text { Load } \\
25 \%\end{array}$ & $\begin{array}{c}\text { Load } \\
50 \%\end{array}$ & Loaf 75\% & $\begin{array}{c}\text { Load } \\
100 \%\end{array}$ \\
$\begin{array}{c}\text { Correlation coefficient of fuel } \\
\text { consumption (r2) }\end{array}$ & 0.9321 & 0.9832 & 0.9856 & 0.9849 & 0.9843 \\
Urban proportion (\%) & 20.6 & 20.4 & 20.3 & 19.5 & 22.4 \\
Suburban ratio (\%) & 25 & 24.1 & 24.8 & 25.1 & 24.5 \\
High speed ratio (\%) & 54.4 & 55.5 & 54.9 & 55.4 & 53.1 \\
WHTC cycle work (multiple) & 5.88 & 8.07 & 7.91 & 7.28 & 6.6 \\
\hline
\end{tabular}

\section{Comparison and analysis of test}

\subsection{Test working condition distribution analysis}


The distribution of the operating conditions of the engine with $10 \%$ load is shown in the figure 1:

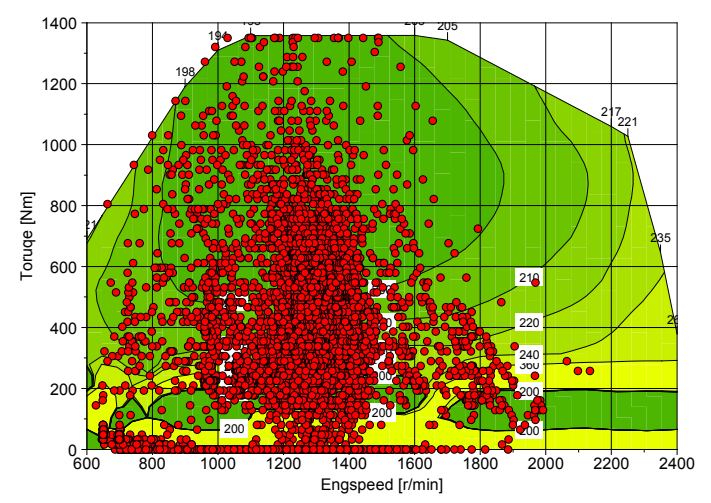

Fig. 1. Operating point distribution at $10 \%$ load.

The distribution of operating conditions of the engine loaded with $25 \%$ load is shown in the figure 2:

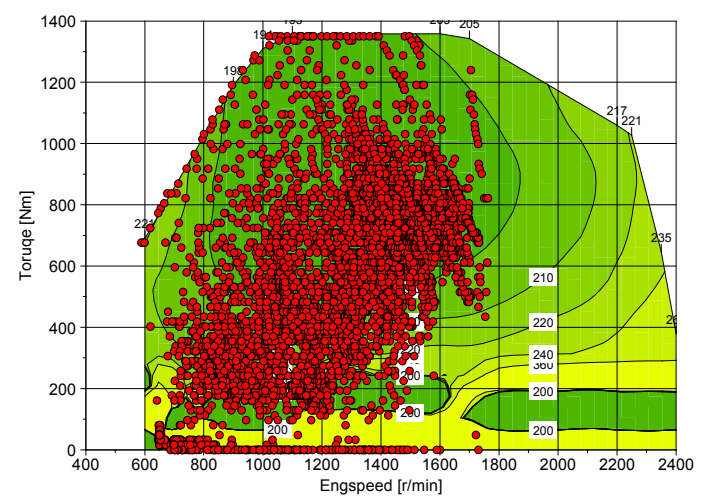

Fig. 2. Operating point distribution at $25 \%$ load.

As can be seen in the figure 2, most of the operating conditions of the engine loaded with $25 \%$ load are concentrated between 1000rpm $\sim 1600 \mathrm{rpm}$, and the operating conditions below $200 \mathrm{Nm}$ are relatively rare. The operating conditions point basically covers all areas of the operating conditions, The maximum speed of the engine is $1800 \mathrm{rpm}$, and the maximum torque of the engine is $1350 \mathrm{Nm}$.

The distribution of the operating conditions of the engine with $50 \%$ load is shown in the figure 3: 


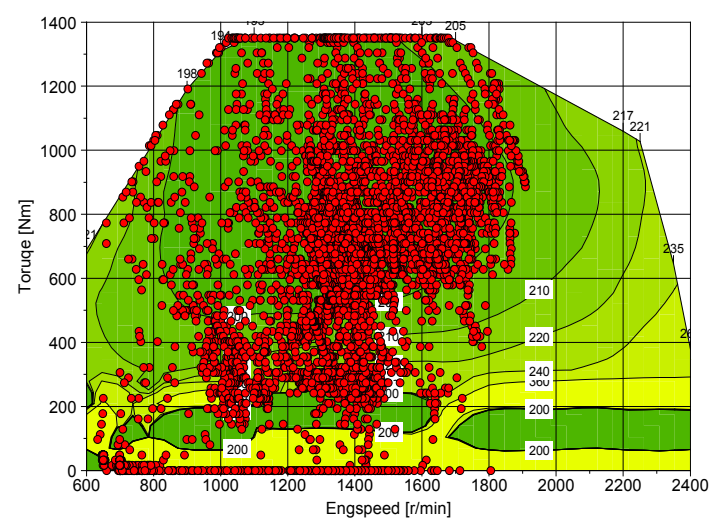

Fig. 3. Operating point distribution at $50 \%$ load.

As can be seen in the figure 3, most of the operating conditions of the engine loaded with $50 \%$ load are concentrated between 1000rpm $\sim 1800 \mathrm{rpm}$, and the operating conditions below $200 \mathrm{Nm}$ are relatively rare. The operating conditions point basically covers all areas of the engine operating conditions. The overall distribution of operating conditions is more uniform. The maximum speed of the engine is $1900 \mathrm{rpm}$, and the maximum torque of the engine is $1350 \mathrm{Nm}$.

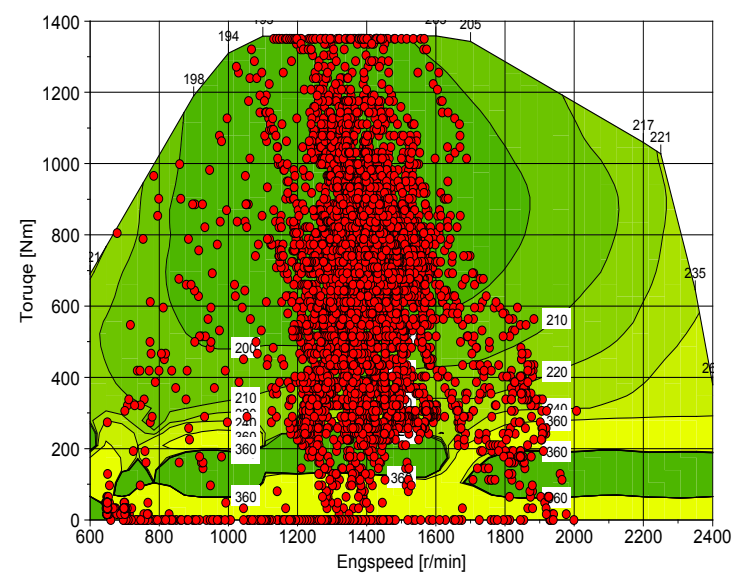

Fig. 4. Operating point distribution at $75 \%$ load.

As can be seen in the figure 4, most of the operating conditions of the engine loaded with $75 \%$ load are concentrated between $1200 \mathrm{rpm} \sim 1600 \mathrm{rpm}$, and the operating conditions below $200 \mathrm{Nm}$ are relatively rare. The operating conditions point basically covers all areas of the operating conditions The overall distribution of operating conditions is more uniform. The maximum speed of the engine is $2000 \mathrm{rpm}$ and the maximum torque of the engine is 1350 $\mathrm{Nm}$. 


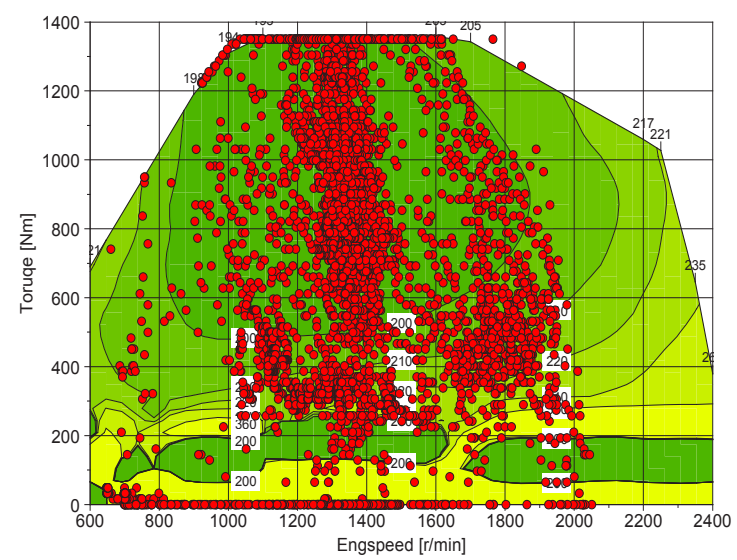

Fig. 5. Operating point distribution at $100 \%$ load.

As can be seen in the figure 5, most of the operating conditions of the engine loaded with $100 \%$ load are concentrated between 1200rpm $\sim 1800 \mathrm{rpm}$, and the operating conditions below $200 \mathrm{Nm}$ are relatively rare. The operating conditions point basically covers all areas of the operating conditions The overall distribution of operating conditions is more uniform. The maximum speed of the engine is $2050 \mathrm{rpm}$ and the maximum torque of the engine is $1350 \mathrm{Nm}$.

The distribution of engine operating conditions depends on the speed ratio of the gearbox. For manual gearboxes, the driver's shifting speed will affect the frequency distribution of the operating speed range of operating conditions. As can be seen from the test data This model has an engine speed limit of $2050 \mathrm{rpm}$ and a maximum engine torque of $1350 \mathrm{Nm}$.

\subsection{Test Analysis of emission test results}

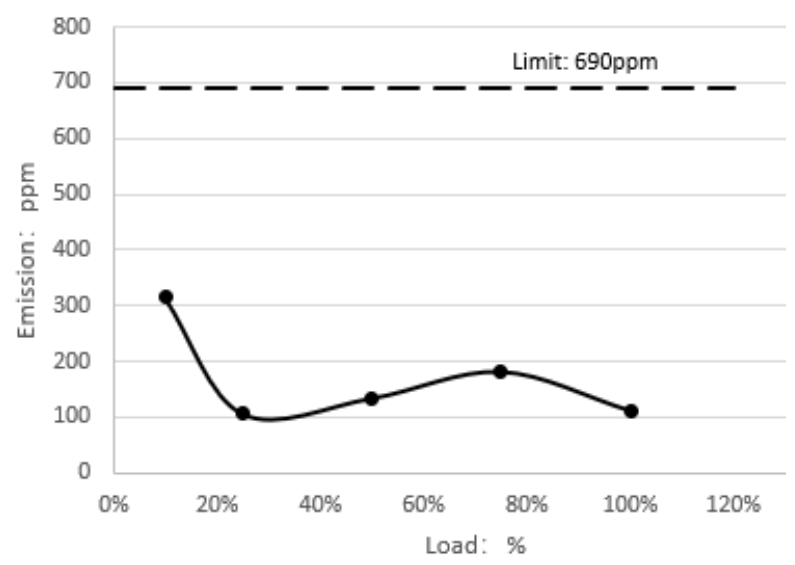

Fig. 6. NOx emissions under different loads.

It can be seen from Figure 5 that NOx emissions show a non-linear change with loading changes. The $10 \%$ loading of NOx emissions is the highest, and the $10 \%$ loading is also the minimum loading boundary required by regulations.

The vehicle's NOx emissions are determined by the original emissions of the engine itself and the NOx conversion efficiency in the SCR aftertreatment. The reduction space of the engine's original exhaust is small, and the NOx conversion efficiency of the SCR post- 
treatment is very high, and under appropriate conditions, the conversion efficiency can reach more than $95 \%$. The main influencing factors of SCR conversion efficiency are the exhaust temperature of the engine, the amount of urea injected and the degree of mixing. The hardware of the mixer on the vehicle has been solidified, the urea injection temperature is set, and the exhaust temperature of the engine has become the main factor affecting the vehicle's NOX emissions. The following compares and analyzes the exhaust temperature of the tail pipe of the vehicle with $10 \%, 25 \%, 50 \%, 75 \%$, and $100 \%$ loads:

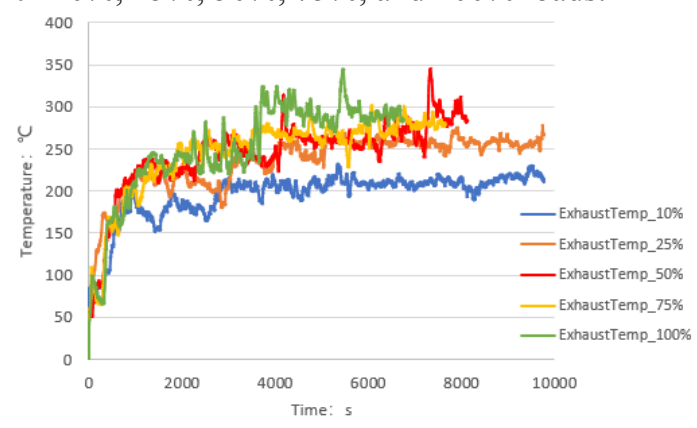

Fig. 7. Comparison of exhaust temperature under different loads.

It can be seen from the figure above that the exhaust temperature level of $10 \%$ loading is the lowest under several loading conditions, and the NOX emission level is the highest under several loading conditions. Therefore, during the development of the national VI compliance of heavy-duty tractors, for the boundary condition of $10 \%$ loading, the focus is on more optimized thermal management, so that the SCR can be in a better operating temperature range and reduce the actual road. Risk of NOX emissions exceeding standards.

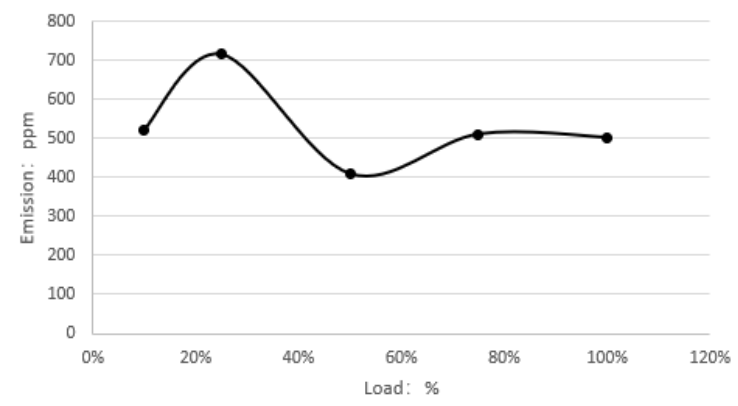

Fig. 8. CO emissions under different loads.

It can be seen from the above figure that under the conditions of PEMS cycle that meets the requirements of the national VI regulations, the car can meet the national VI b regulations under the load of $10 \%, 25 \%, 50 \%, 75 \%$, and $100 \%$. The requirements of the limits and can leave a lot of margin. $\mathrm{CO}$ emissions show a non-linear change with loading changes, with $25 \% \mathrm{CO}$ emissions being the highest and 50\% CO emissions being the lowest.

The CO emissions of the entire vehicle depend on the conversion efficiency of the engine's original exhaust and DOC in the aftertreatment. The optimal working temperature of DOC is $250^{\circ} \mathrm{C} \sim 350^{\circ} \mathrm{C}$. After the engine water temperature reaches $70^{\circ} \mathrm{C}$ in the test, the internal measurement temperature of the DOC is within the optimal working temperature range. Under different loading conditions, the DOC conversion efficiency can reach more than $90 \%$. The difference in CO emissions of the vehicle under different loadings is mainly reflected in the difference in the original row. Therefore, during the development of the national VI compliance of heavy tractors, the control of CO emissions must first optimize the in-cylinder emissions of the engine and install DOC at the vehicle level to verify. 


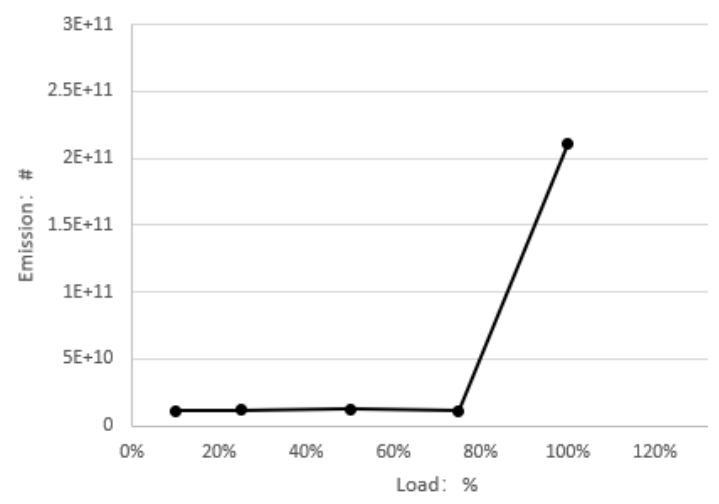

Fig. 9. PN emissions under different loads.

It can be seen from Figure 9 that under the conditions of the PEMS cycle that meets the requirements of the national six regulations, under the load of $10 \%, 25 \%, 50 \%, 75 \%$, and $100 \%$, the PN emission of particulate matter varies with the loading The change of $\mathrm{N}$ is nonlinear, and the amount of particulate matter PN is the largest when the load is $100 \%$.

The amount of particulate matter PN mainly depends on the working conditions of the DPF module in the engine's original exhaust and aftertreatment equipment. Under normal circumstances, the DPF can filter out $95 \%$ of the particulate matter PN. The study found that the emission of particulate matter PN The amount is inversely proportional to the exhaust flow of the engine. The exhaust flow is the largest under the condition that the vehicle is loaded with $100 \%$ load, so that the amount of particulate matter PN is also the highest under the condition of $100 \%$ load in emissions. As shown in the following table: During the development of the country 's six heavy-duty tractors, the focus of the development of PN on the amount of particulate matter is to ensure the normal regeneration of DPF under the premise of reasonable selection, so as to maintain the actual filtration efficiency of DPF and the amount of particulate matter. The risk of PN is minimized.

Table 1. Average air flow rate of aftertreatment pipeline under different loads.

\begin{tabular}{lc}
\hline Load & Average exhaust flow rate \\
\hline Load $10 \%$ & 4.41 \\
Load $25 \%$ & 5.13 \\
Load $50 \%$ & 6.04 \\
Load $75 \%$ & 6.22 \\
Load $100 \%$ & 6.312 \\
\hline
\end{tabular}

\section{Conclusion}

Based on the requirements of the actual road test regulations of the National Sixth Standard, a certain heavy-duty tractor has carried out PEMS cycle tests on actual roads at different loads of $10 \%, 10 \%, 25 \%, 50 \%, 75 \%$, and $100 \%$. The comparison test data shows that the operating conditions of the engine on the actual road are significantly different from the operating conditions of the WHTC cycle of the national six engine. For tractors at $10 \%, 25 \%$, $50 \%, 75 \%$, and $100 \%$, respectively. The distribution characteristics of the engine operating conditions points required by the national road regulations under actual roads under load are compared and analyzed. The distribution of engine operating conditions points under different loads is different. 
The comparative analysis of the emission conditions required by the State Road 6 regulations of the actual roads under $10 \%, 25 \%, 50 \%, 75 \%$, and $100 \%$ loading of the tractor is performed. The reason for the highest emissions is the high-risk loading conditions during development. The optimization of NOX emissions during development focuses on the control of thermal management of the exhaust temperature at $10 \%$ loading; the correlation between $\mathrm{CO}$ emissions and loading conditions It is not very large, it mainly depends on the optimization of the original $\mathrm{CO}$, and the normal ignition conditions of the post-processor DOC are met. During the development of National VI, the focus was on the maximum optimization of $\mathrm{CO}$ on the engine bench; the particulate matter amount PN emission was a high-risk loading condition under 100\% loading. The compliance development for the particulate matter amount PN focused on the engine cylinder emissions Optimization, activation of DPF normal regeneration.

This work was supported by the key project of China Automotive Technology \& Research Center (17180109) and the project of CATARC Automotive Test Center (Tianjin) Co.,Ltd(TJKY1718009).

\section{References}

1. Gao Qingwen, Cui Huifeng, Wu Shijing. Experimental Study and Optimization of National Road Heavy-duty Diesel Vehicle Emissions [J]. Internal Combustion Engine, 2018 (06): $15-17+21$.

2. Song Jinghao, $\mathrm{He}$ Liqiang, $\mathrm{Hu}$ Jingnan, $\mathrm{Hu}$ Kaijian, $\mathrm{Du}$ Yan, $\mathrm{Zu}$ Lei, Bao Xiaofeng.Actual road emission characteristics of China II heavy-duty diesel trucks under different load conditions [J] .Environmental Pollution \& Control, 2019,41 (01): 34-40.

3. Song Jinghao, He Liqiang, $\mathrm{Hu}$ Jingnan, $\mathrm{Hu}$ Kaijian, $\mathrm{Du}$ Yan, $\mathrm{Zu}$ Lei, Bao Xiaofeng.Actual road emission characteristics of China II heavy-duty diesel trucks under different load conditions [J] .Environmental Pollution \& Control, 2019,41 (01): 34-40.

4. Tan Jianxun, Wang Zhiwei, Li Wei, Jiang Xijun.Experimental Study on EGR and DOC to Realize Euro IV Emissions of Diesel Engine [J] .Automobile Technology, 2011 (07): 10-13.

5. Liu Hongwei, Zhang Kaikai, Yao Guangtao, Zhang Weifeng, Zi Xinyun.Research on DOC-assisted DPF regeneration technology using in-cylinder rear injection and exhaust pipe injection [J] .Automotive Engineering, 2015,37 (04): 391-395. 